\title{
Mechanistic Study of Nucleation Enhancement in Atomic Layer Deposition by Pre- Treatment with Small Organometallic Molecules
}

Camila de Paula, Nathaniel E. Richey, Li Zeng, and Stacey F. Bent ${ }^{\star}$

Department of Chemical Engineering, Stanford University, Stanford, California 943055025, United States

* Corresponding author email: sbent@stanford.edu

\section{Abstract}

Thermal atomic layer deposition (ALD) of metals on metal oxide surfaces typically suffers from nucleation delays that result in poor-quality films. The poor nucleation may be caused by a lack of suitable chemisorption sites on the oxide surface which are needed for metal nucleation to occur. In this work, we demonstrate that pre-functionalizing the surface with a sub-monolayer of small organometallic molecules from the vapor phase can lead to a significant increase in surface coverage of the metal deposited by ALD. This process is demonstrated for Pt ALD from (methylcyclopentadienyl)trimethylplatinum ( $\mathrm{MeCpPtMe}_{3}$ ) and $\mathrm{O}_{2}$, with nucleation enhanced almost three-fold at $100 \mathrm{ALD}$ cycles after the pre-treatment. We hypothesize that the high coverage of the organometallic molecule provides an alternative chemisorption mechanism for the platinum precursor and thus leads to an increase in its uptake. The proposed chemisorption mechanism is robust across several organometallic molecule pre-treatments and could potentially be exploited for other organometallic-based metal ALD processes. The growth of the platinum deposits was investigated in depth though scanning electron microscopy (SEM) and grazing incidence small angle $x$-ray scattering (GISAXS). These studies show that the pretreatment results in the growth of larger, denser and more highly ordered Pt nanoparticles at early cycle numbers, which subsequently coalesce into continuous and pinhole free 
films. Surface pre-treatment by organometallic molecules therefore introduces a potential route to achieve improved nucleation and growth of ultrathin films.

\section{Introduction}

Atomic layer deposition (ALD) is a surface sensitive thin film deposition technique that has seen rapid development for a wide variety of applications, e.g. in microelectronics, ${ }^{1}$ catalysis, ${ }^{2}$ and energy technologies. ${ }^{3}$ By utilizing a series of self-limiting surface reactions, the ideal ALD process deposits films in a layer-by-layer growth mechanism, thus providing control over film conformality and thickness at the atomic scale. ${ }^{4}$ Nevertheless, a significant fraction of ALD film-substrate systems have non-idealities that impede layerby-layer film growth. Competing growth mechanisms such as island growth (Volmer Weber) result in dispersed nanoparticles (NPs) that form a continuous, but not always pinhole-free, film upon coalescence of the NPs. ${ }^{5}$ Non-idealities leading to NP nucleation and growth are typical of thermal metal ALD on low surface energy substrates and are especially prominent in the case of noble metal ALD on oxide substrates. ${ }^{6}$ This island growth imposes a challenge for applications where ultrathin metal films are needed, such as $\mathrm{Ru}$ electrodes in high aspect ratio structures for DRAM, ${ }^{7}$ Pt catalysts in protonexchange membrane fuel cells, ${ }^{8}$ and others. There are many motivations for improving control over the film growth mechanism, e.g., noble metals are scarce and expensive, thus maximizing cost-effectiveness is of high economic value; and, further miniaturization in the semiconductor industry requires the ability to deposit ultrathin, pinhole-free metal films with high conformality. ${ }^{9}$

The non-idealities that are associated with thermal ALD of noble metals on oxide substrates are largely due to a lack of chemisorption sites and poor wettability of the high 
surface energy metal on low energy oxide surfaces. The use of small molecules for surface activation has shown promise in improving the nucleation of noble metal ALD. Goldstein and George ${ }^{10}$ reported the use of trimethyl aluminum ( $\mathrm{AlMe}_{3}$ ) to remove a surface-poisoning species, $\mathrm{Al}(\mathrm{hfac})_{\mathrm{x}}$, during palladium $\mathrm{ALD}$ from palladium hexafluoroacetylacetonate $\left[\mathrm{Pd}(\mathrm{hfac})_{2}\right]$ and formalin on $\mathrm{Al}_{2} \mathrm{O}_{3}$ substrates. They proposed that $\mathrm{AlMe}_{3}$ promotes a ligand exchange reaction that results in the removal of $\mathrm{Al}(\mathrm{hfac})_{x}$ as $\mathrm{Al}(\mathrm{hfac})_{3}$ and regenerate the chemisorption sites for further $\mathrm{Pd}(\mathrm{hfac})_{2}$ adsorption. Minjauw et al. ${ }^{11}$ used $\mathrm{AlMe}_{3}$ pre-treatment during $\mathrm{Ru} A L D$ from $\mathrm{RuO}_{4}$ and $\mathrm{H}_{2}$ to enhance $\mathrm{Ru}$ nucleation on $\mathrm{SiO}_{2}$. The organic ligands of the adsorbed $\mathrm{AlMe}_{3}$ precursor are readily oxidized by $\mathrm{RuO}_{4}$, which results in facile Ru nucleation. Hwang et al. ${ }^{12}$ reported some degree of nucleation enhancement by pre-pulsing $\mathrm{AlMe}_{3}$ prior to 200 cycles of plasmaenhanced Pt ALD from trimethyl(methylcyclopentadienyl)platinum ( $\left.\mathrm{MeCpPtMe}_{3}\right)$ and $\mathrm{O}_{2}$ on a $\mathrm{SiO}_{2}$ substrate. They state that an intermediate number of $\mathrm{AlMe}_{3}$ pre-pulses ( 40) prior to deposition leads to enhanced Pt nucleation, whereas a larger number of $\mathrm{AlMe}_{3}$ pre-pulses $(\sim 100)$ poisons the surface and causes delayed Pt film coalescence. The authors hypothesize that the low-coverage adsorbed $\mathrm{AlMe}_{3}$ provides a wetting layer which helps the layer-by-layer growth mode, whereas the higher number of $\mathrm{AlMe}_{3}$ prepulses poisons the surface by forming inert Al-O-Al bonds which in turn inhibit Pt growth. Because oxygen plasma is well-known to combust methyl ligands during $\mathrm{Al}_{2} \mathrm{O}_{3} \mathrm{ALD}$ and create hydroxyl surface sites, the interaction between the oxygen plasma and the predosed $\mathrm{AlMe}_{3}$ species could provide another potential explanation for the enhancement observed by Hwang et al. ${ }^{13}$ 
Other previous studies have also shown that increasing the number of surface hydroxyl sites can help to control and improve the nucleation of Pt ALD. These hydroxyls have been postulated to be a key component of the chemisorption of $\mathrm{MeCpPtMe}_{3}$, due to their ability to act both as a Lewis base and a Brønsted acid in the ligand exchange between the $\mathrm{MeCpPtMe}_{3}$ and the oxide substrate surface. ${ }^{14-16}$ Thus, increasing the density of surface hydroxyls can provide additional chemisorption sites, as well as increase their Brønsted acidity through hydrogen bonding. ${ }^{17}$ It has been established that many of the common metalorganic precursors for metal oxide ALD are more reactive than many of the noble metal precursors toward the hydroxyl groups as well as bridged oxygens that are present at the surface of oxide substrates. ${ }^{18-20}$ This reactivity results in pinhole-free films of the deposited metal oxide after a few cycles of ALD growth. If these ALD grown metal oxide films have a higher concentration of active sites for chemisorption (such as hydroxyl groups) than the underlying substrate, then even a thin coating of ALD metal oxide on an otherwise nucleation site-poor surface can lead to enhanced Pt growth, as described in previous studies that used $25-30$ cycles of $\mathrm{Al}_{2} \mathrm{O}_{3} \mathrm{ALD}$ as adhesion layers to facilitate Pt growth on polymer substrates such as polyethylene naphtalene..$^{21,22}$

Dameron et al. ${ }^{23}$ demonstrated that functionalizing carbon nanotubes (CNTs) with $\mathrm{AlMe}_{3}$ prior to $\mathrm{Pt}$ deposition from $\mathrm{MeCpPtMe}_{3}$ and $\mathrm{O}_{2}$ leads to enhanced Pt nucleation on the defect sites of the outer surface of the CNTs. The authors postulated that since Pt ALD growth on graphitic substrates suffers from an extensive nucleation delay, ${ }^{24} \mathrm{Al}-\mathrm{OR}$ groups may form during the exposure to $\mathrm{O}_{2}$ at elevated temperatures, $250^{\circ} \mathrm{C}$, which may then act as favorable nucleation sites for $\mathrm{MeCpPtMe}_{3}$ adsorption. However, no evidence for the formation of Al-OR species or a hypothesis of how they would react with the $\mathrm{Pt}$ 
precursor was given. Overall, although small molecule pre-treatments have shown promise in enhancing the nucleation of noble metals, these treatments suffer from either a lack of robustness, being quite substrate or precursor specific, or incomplete understanding of the chemical mechanism.

In this work, we study the influence of a sub-monolayer surface coverage of several small organometallic and metal halide molecules on the nucleation and growth of Pt by ALD, as a model system. Thermal $\mathrm{SiO}_{2}$ was chosen as the substrate, to demonstrate the treatment's efficacy on a moderately hydroxylated surface that does not inherently suffer from extended nucleation delays. Scanning electron microscopy (SEM) and synchrotron based grazing incidence small angle X-ray scattering (GISAXS) were used to investigate the ALD growth mechanism on various treated and untreated substrates. The proposed growth mechanism and potential reaction pathway show that increasing the surface Lewis acidity and Brønsted basicity is a promising method for nucleation enhancement. The results show that this molecular surface pre-treatment exerts a strong influence on Pt ALD nucleation, yielding up to a 2.7-fold increase in Pt surface coverage at 100 cycles of Pt ALD. In addition, the treatment increases the degree of wetting of Pt nanoparticles, indicating a possible increase of the adhesion energy between the metal and the treated surface.

\section{Results and Discussion}

As described above, pre-deposition of a metal-oxide film by ALD can lead to enhanced Pt growth by ALD. We were able to reproduce a similar nucleation enhancement as that reported for $\mathrm{Al}_{2} \mathrm{O}_{3} \mathrm{ALD}$ films with a single $\mathrm{AlMe}_{3}+\mathrm{H}_{2} \mathrm{O}$ cycle prior to $\mathrm{Pt} A L D$, as shown in Figure $1 \mathrm{a}$ and $1 \mathrm{~b}$. This result is not unexpected, because by dosing an ALD half cycle of 
a reactive metalorganic precursor, such as $\mathrm{AlMe}_{3}$, onto a substrate that has low hydroxyl density (such as thermally grown $\mathrm{SiO}_{2}$ ) followed by a $\mathrm{H}_{2} \mathrm{O}$ half cycle, the overall hydroxyl density can be increased compared to the original substrate. ${ }^{25,26}$ Importantly, we also observed in the current study that a carefully controlled dose of $\mathrm{AlMe}_{3}$ alone, without exposure to any $\mathrm{H}_{2} \mathrm{O}$, can lead to a comparable enhancement of nucleation (Figure 1c). The Pt coverages after 100 cycles of Pt ALD for the untreated and pre-treated substrates were determined from the SEM images presented in Figure 1. The calculated apparent coverages (defined as the area covered by Pt ratioed to the total area; see experimental section for more details) are 34\% for the untreated substrate, and between $90-97 \%$ for both treated substrates.
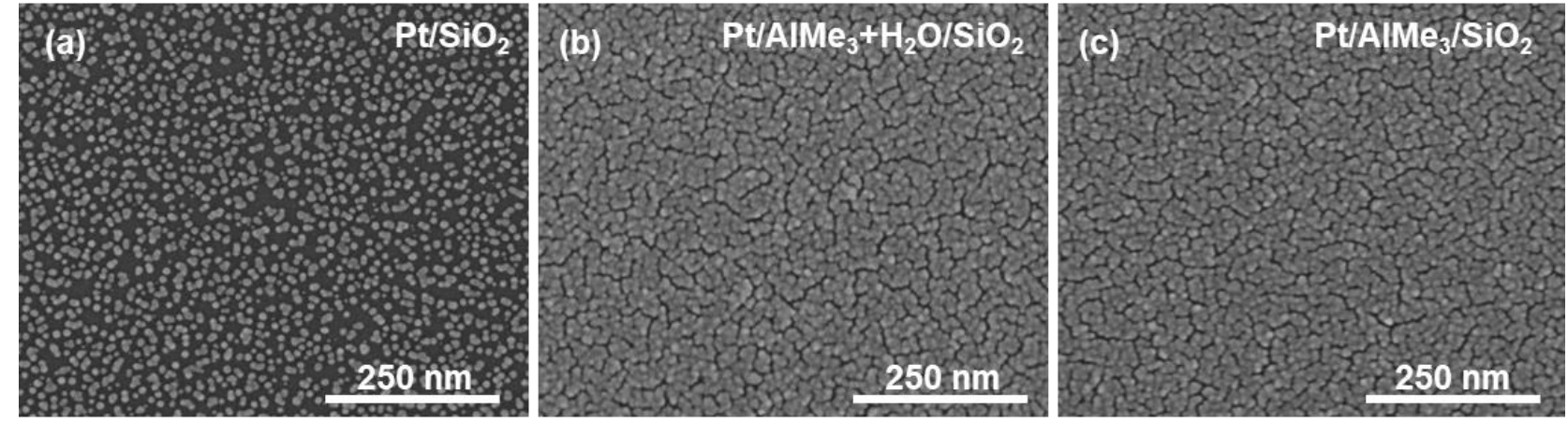

Figure 1. SEM images taken after 100 cycles of Pt ALD on a thermal $\mathrm{SiO}_{2}$ substrate that is (a) untreated, (b) treated with AIMe 3 and $\mathrm{H}_{2} \mathrm{O}$, and (c) treated with a single pulse of $\mathrm{AlMe}_{3}$.

To quantify the enhancement effect, we define an enhancement factor (EF) as the ratio of Pt coverage on a treated substrate to Pt coverage on the untreated substrate, as measured by SEM. According to this metric, the EF of both treated substrates shown in Figure 1 is approximately 2.7 (i.e. $~ 94 \% / 34 \%$ ). Table 1 compares the coverages and EFs calculated at 100 cycles of Pt ALD at $300{ }^{\circ} \mathrm{C}$ on surfaces pre-treated with the various metalorganic and inorganic precursors used in these studies, and Figure 2 presents SEM 
images after 100 cycles of $\mathrm{Pt} A L D$ on a thermal $\mathrm{SiO}_{2}$ substrate treated with a single pulse of $\mathrm{AICl}_{3}, \mathrm{TiCl}_{4}$, and $\mathrm{ZnEt}$, with resulting EFs as shown in Table 1 of 1.5 and 1.2, and 2.7 respectively. It is evident from the data in Table 1 that 1 ) each of the metalorganic and inorganic precursors shows some enhancement effect on Pt ALD, and 2) there are important differences in the level of enhancement depending on the identity of the precursor. Noticeably, the $\mathrm{AlMe}_{3}, \mathrm{AlMe}_{2} \mathrm{Cl}$, and $\mathrm{ZnEt} 2$ coordination complexes all lead to a greater degree of nucleation enhancement than do $\mathrm{AlCl}_{3}$ and $\mathrm{TiCl}_{4}$.

Table 1. Summary of the metalorganic and inorganic precursors used for surface functionalization and their respective EFs at 100 cycles of Pt ALD

\begin{tabular}{c|c|c}
\hline Surface Functionalization & $\begin{array}{c}\text { Apparent } \\
\text { Coverage (\%) }\end{array}$ & EF \\
\hline Untreated Substrate $\left(300^{\circ} \mathrm{C}\right)$ & 34 & - \\
AlMe$_{3}$ & $90-97$ & 2.7 \\
AlMe$_{2} \mathrm{Cl}$ & $90-97$ & 2.7 \\
ZnEt2 $_{2}$ & $90-97$ & 2.7 \\
$\mathrm{AlCl}_{3}$ & 50 & 1.5 \\
$\mathrm{TiCl}_{4}$ & 42 & 1.2 \\
\hline
\end{tabular}
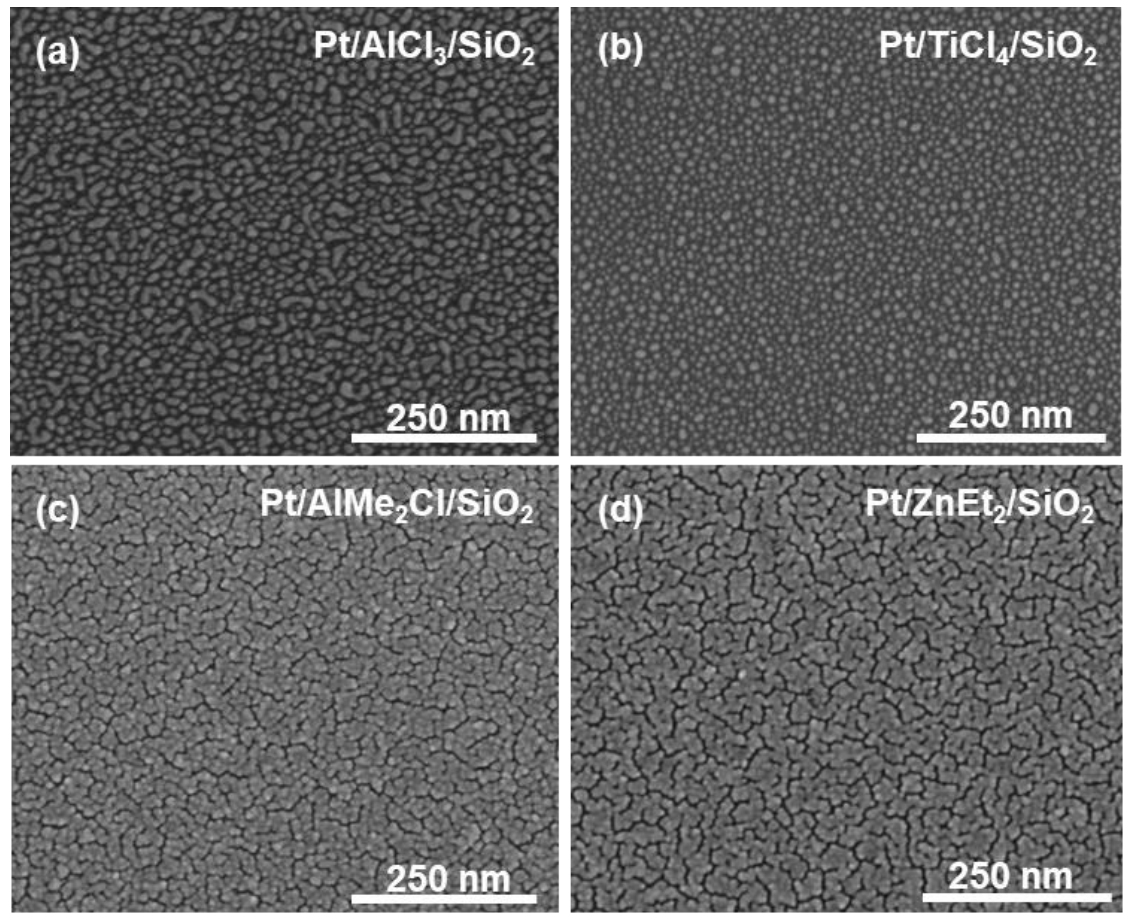

Figure 2. SEM images of 100 cycles of Pt ALD on a thermal $\mathrm{SiO}_{2}$ surface treated with 1 pulse of (a) $\mathrm{AlCl}_{3}$ (b) $\mathrm{TiCl}_{4}(\mathrm{c}) \mathrm{AlMe}_{2} \mathrm{Cl}$ (d) $\mathrm{ZnEt}_{2}$ 
To better understand the role that the metalorganic and purely inorganic precursors are playing in enhancing Pt ALD, we return to the case of $\mathrm{AlMe}_{3}$ pre-treatment. The data in Figure 1 show that both $\mathrm{AlMe}_{3}+\mathrm{H}_{2} \mathrm{O}$ and $\mathrm{AlMe}_{3}$-only cycles lead to Pt ALD nucleation enhancement. The $\mathrm{AlMe}_{3}+\mathrm{H}_{2} \mathrm{O}$ cycle is well known to generate $\mathrm{Al}_{2} \mathrm{O}_{3}$ at the surface, and as described above, an $\mathrm{Al}_{2} \mathrm{O}_{3}$ surface layer can enhance Pt ALD. ${ }^{21}$ That leaves the question of what is the effect of $\mathrm{AlMe}_{3}$ only? Does it simply lead to formation of $\mathrm{Al}_{2} \mathrm{O}_{3}$, or can $\mathrm{AlMe}_{3}$ adsorbates themselves enhance Pt ALD? Prior to Pt ALD, adsorbed $\mathrm{AlMe}_{3}$ can in principle react further to generate $\mathrm{Al}_{2} \mathrm{O}_{3}$ or related species such as $\mathrm{Al}(\mathrm{OH})_{x}$ through several pathways, including precursor hydroxylation due to trace moisture, exposure to $\mathrm{O}_{2}$, and ligand pyrolysis. We tested for growth of $\mathrm{Al}_{2} \mathrm{O}_{3}$ using $\mathrm{AlMe}_{3}$ under the conditions used for the Pt ALD process and found that no significant $\mathrm{Al}_{2} \mathrm{O}_{3}$ growth occurred, ruling out the possibility that $\mathrm{Al}(\mathrm{OH}) \times$ or $\mathrm{Al}-\mathrm{O}-\mathrm{Al}$ was responsible for the observed enhancement (see the SI for more information). The self-limiting behavior of the other Al, $\mathrm{Zn}$ and Ti precursors was verified in a similar manner. Therefore, we posit that chemisorbed $\mathrm{AlMe}_{3}$ fragments directly influence the reaction pathway of the $\mathrm{MeCpPtMe}_{3}$ precursor.

To understand the mechanism by which $\mathrm{AlMe}_{3}$ facilitates reaction of $\mathrm{MeCpPtMe}$, we consider the acid-base behavior of the two molecules. Given that Al is a strong Lewis acid, and $\mathrm{AlMe}_{3}$ is highly reactive towards surface hydroxyls, ${ }^{27}$ after the AlMeз half-cycle the surface is expected to be Lewis acidic, with most Brønsted acidic hydroxyl sites on the surface consumed by the AlMes ${ }^{26}$ Since the surface is deprived of Brønsted acid hydroxyls, the enhanced growth of $\mathrm{Pt}$ from $\mathrm{MeCpPtMe}_{3}$ on the $\mathrm{AlMe}_{3}$-functionalized surface cannot be explained through the classical Brønsted acid-base ligand exchange 
mechanism, in which an acidic surface proton promotes the ligand exchange reaction as illustrated in Figure 3a. As a result, we conclude that the enhanced growth of Pt must be attributed to an alternative reaction mechanism.

To further elucidate the reaction mechanism that causes the Pt nucleation enhancement, we return to examine the influence of the four other metalorganic and inorganic precursors on Pt ALD. These include two Lewis acidic halogenated precursors, $\mathrm{AlCl}_{3}$ and $\mathrm{TiCl}_{4}$, a Lewis acidic precursor that has both methyl and halogen ligands, $\mathrm{AlMe}_{2} \mathrm{Cl}$, as well as a weaker Lewis acid that contains a metal-alkyl bond, ZnEt2. As presented in Table 1, an enhancement is seen after pre-dosing with each metalorganic and inorganic precursor, but the enhancement clearly differs for the different molecules.

The comparison across the five different metalorganic and inorganic precursors applied to the same noble metal ALD process gives important insight into the mechanism. Considering the chemical nature of the functionalized surface, after pre-dosing of any of the five metalorganic and inorganic precursors, the surface will be depleted of the Lewis basic/Brønsted acidic hydroxyl groups that normally participate in $\mathrm{MeCpPtMe}$ adsorption onto the surface. Although the surface becomes Lewis acidic upon exposure to two of the metalorganic precursors that lead to significant nucleation enhancement (AlMes and $\mathrm{AlMe}_{2} \mathrm{Cl}$ ), we do not believe this plays a key role in the subsequent $\mathrm{MeCpPtMe}_{3}$ chemisorption. If Lewis acidity were the dominant effect, we would expect $\mathrm{AlCl}_{3}$ and $\mathrm{TiCl}_{4}$, also strong Lewis acids, to show the same enhancement effect. Moreover, we would expect ZnEt2, a significantly weaker Lewis acid, to show much less enhancement. ${ }^{28,29}$ However, the data in Table 1 are not consistent with such predictions; rather, $\mathrm{AlCl}_{3}$ and $\mathrm{TiCl}_{4}$ show much lower enhancement while $\mathrm{ZnEt} 2$ shows the same $\mathrm{EF}$ as $\mathrm{AlMe}_{3}$ and 
$\mathrm{AlMe}_{2} \mathrm{Cl}$. It is possible that differences in surface coverages of the pre-pulsed metalorganic or inorganic precursor could partly compensate for Lewis acidity effects and influence the resulting EF. Given that $\mathrm{ZnEt}_{2}$ is a significantly weaker Lewis acid than $\mathrm{AlMe}_{3}$, only a considerably higher surface coverage of $\mathrm{ZnEt}_{2}$ compared to $\mathrm{AlMe}_{3}$ would account for their similar enhancement of Pt ALD if Lewis acidity played a key role in MeCpPtMe 3 adsorption. However, it has been shown that $\mathrm{AlMe}_{3}$ consumes all hydroxyl and siloxane bridge surface sites upon adsorption to silica. ${ }^{30}$ It is therefore unlikely that a significantly higher surface coverage of $\mathrm{ZnEt} 2$ is achieved and could account for the large EF observed.

Rather than Lewis acidity effects, the behavior may be correlated instead with the presence of organic ligands on the pre-treatment precursor. It is evident from Table 1 that the purely chlorinated precursors exhibit significantly lower enhancement than do precursors that contain alkyl ligands, which show higher enhancement. We postulate, therefore, that the chemisorption mechanism of $\mathrm{MeCpPtMe}_{3}$ on the pre-treated surface is tightly related to the metal-alkyl bond in the metalorganic. Previous studies have reported hydrogen abstraction from metal-bonded alkyl ligands in the presence of alkylaluminates, ${ }^{31-34}$ a process illustrated in Figure $3 \mathrm{~b}$. The significantly lower electronegativity of $\mathrm{Zn}$ and $\mathrm{Al}$ compared to that of $\mathrm{Pt}$ makes the Al-alkyl and $\mathrm{Zn}$-alkyl bonds more ionic nature and their ligands stronger Brønsted bases than the organic ligands of $\mathrm{MeCpPtMe}_{3}$. We hypothesize that this basic alkyl group can abstract a hydrogen from one of the methyl ligands that are bonded to the Pt precursor, as shown in Figure 3d. This hydrogen abstraction would result in the release of $\mathrm{CH}_{4(\mathrm{~g})}$ in the case of the methylated precursors, or $\mathrm{C}_{2} \mathrm{H}_{6(\mathrm{~g})}$ in the case of the ethylated precursor, as a 
byproduct. The remaining methylene could then form a bridge between the Pt and the $\mathrm{Al} / \mathrm{Zn}$, resulting in strong chemisorption to the surface. The proposed mechanism is predicted to be accessible with the $\mathrm{AlMe}_{3}, \mathrm{AlMe}_{2} \mathrm{Cl}$ and $\mathrm{ZnEt} 2$ precursors, consistent with the highest nucleation enhancement for Pt ALD observed for these three molecules.

This proposed mechanism can also explain the lower EF observed for the metal halide precursors, $\mathrm{AlCl}_{3}$ and $\mathrm{TiCl}_{4}$. Since the chloride anion is a significantly weaker Brønsted base than an alkyl anion, hydrogen extraction evolving $\mathrm{HCl}$ and leading to MeCpPtMe 3 chemisorption would be significantly hindered in $\mathrm{AlCl}_{3}$ and $\mathrm{TiCl}_{4}$. However, the strong Lewis acidity of the Al or Ti could still contribute to forming a weak coordination bond to the $\mathrm{MeCpPtMe}_{3}$, as has been observed for supported Lewis acid metal catalysts for olefin hydrogenation..$^{35-37}$ An empty orbital of the adsorbed metal may interact with a bonding pair of electrons from a methyl ligand of the $\mathrm{MeCpPtMe}_{3}$ to form a weak threecentered-two-electron bond, as in Figure 3d, similar to what is observed for the dimer of $\mathrm{AlMe}_{3}$ at room temperature. ${ }^{38}$ The formation of this bond, which could occur in any of the aforementioned precursors, would likely be stronger in the case of the halide precursors due to the electron withdrawing nature of the halogens. This bonding could result in some enhancement, even if the final hydrogen abstraction step (Figure $3 d$ to $3 e$ ) is unfavorable. This three-centered complex could also explain why pre-treatment with $\mathrm{AlCl}_{3}$ shows slightly more enhancement than pre-treatment with $\mathrm{TiCl}_{4}$, as the empty $2 \mathrm{p}$ orbital of the $\mathrm{Al}$ in $\mathrm{AlCl}_{3}$ is less sterically crowded. Alternatively, the slight difference in enhancement observed with $\mathrm{TiCl}_{4}$ versus $\mathrm{AlCl}_{3}$ may be a result of their relative reactivity with the surface. $\mathrm{TiCl}_{4}$ is known to preferentially react bifunctionally with vicinal hydroxyls rather than with isolated hydroxyls. ${ }^{27}$ Since thermally grown $\mathrm{SiO}_{2}$ is used as the growth surface in these 
experiments, these vicinal sites may be less abundant on the surface, ${ }^{39}$ and so one pulse of $\mathrm{TiCl}_{4}$ may lead to a lower coverage on the substrate than $\mathrm{AlCl}_{3}$.

(a)

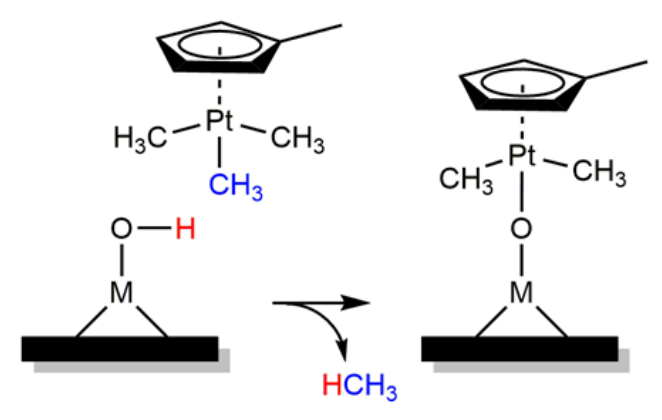

(c)

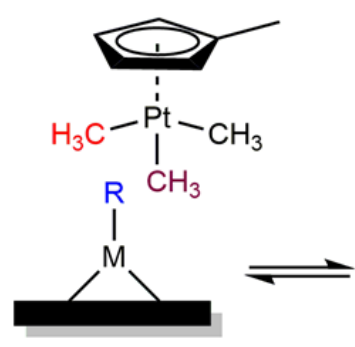

(d)

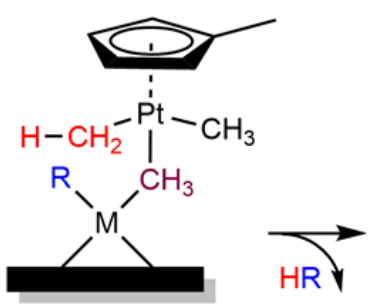

(b)<smiles>CCCCCCCCCCCCCC</smiles><smiles>C[Al]1(C)C[14CH2][14CH2]1</smiles>

(e)

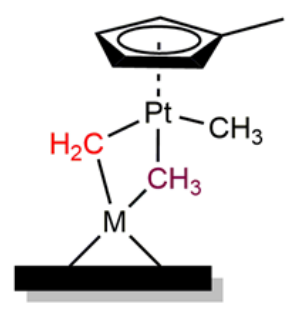

Figure 3. (a) Brønsted acid-base ligand exchange between a surface hydroxyl and $\mathrm{MeCpPtMe}_{3}$ b) Hydrogen abstraction from metalbonded alkyl ligands in the presence of alkylaluminates observed in literature, where $\mathrm{M}$ is a metal such as $\mathrm{La}, \mathrm{Ti}$ and $\mathrm{Zr}$, and $\mathrm{L}_{x}$ represent non-reacting ligands. (c)-(e) Proposed hydrogen abstraction pathway between M-R and MeCpPtMe $e_{3}$, where $\mathrm{M}$ is $\mathrm{Al}, \mathrm{Zn}$ or $\mathrm{Ti}$, and $\mathrm{R}$ is $\mathrm{CH}_{3},-\mathrm{CH}_{2} \mathrm{CH}_{3}$ or $-\mathrm{Cl}$

We have proposed that surface pre-treatment with organometallic precursors can lead to an alternative chemisorption mechanism in Pt ALD. However, we must also consider another factor that could contribute to the enhanced Pt coverage observed: the wetting/adhesion properties of the growing metal to the functionalized surface. Generally, stronger adhesion of the metal to the substrate is linked to lower surface diffusivity of the metal NPs and can lead to an increase in the loading of the deposited metal. To 
investigate if the organometallic surface treatment causes alterations to the growth mechanism that could be responsible for the enhanced growth, the initial stages of growth were studied by collecting SEM images and grazing incidence small angle scattering (GISAXS) patterns as a function of ALD cycle number. SEM images allow for 2D realspace analysis of average particle size and coverage during growth. GISAXS is a complementary and versatile technique that provides information on particle size and shape, interparticle correlation, three-dimensional geometry, and lateral ordering of particles on the surface. ${ }^{40-42}$ The full evolution of SEM images and GISAXS patterns during growth can be found in the supporting information (Figures S1, S2 and S4). Figure 4 presents the 2D GISAXS image, the horizontal and vertical line cuts of the GISAXS data and their fit, and SEM images for two samples: (a-d) untreated thermal $\mathrm{SiO}_{2}$ followed by 40 cycles of Pt ALD, and (e-h) thermal $\mathrm{SiO}_{2}$ treated with 1 pulse of $\mathrm{AlMe}_{2} \mathrm{Cl}$, followed by 30 cycles of Pt ALD. The number of Pt ALD cycles differed slightly between the two samples because in the case of the untreated substrates, strong signal and clear interparticle correlation peak were achieved after 40 cycles, whereas at 40 cycles on the treated substrate there was already evidence of significant film coalescence.

The GISAXS data was fitted in the $q_{y}$ and $q_{z}$ directions simultaneously under the assumption of the distorted wave-born approximation, as described in the Experimental Methods section. The GISAXS fit parameters and SEM analysis results for the data presented in Figure 4 are summarized in Table 2. Data in the $q_{y}$ direction givel information about the in-plane NP diameter and geometry, center-to-center interparticle distance, and degree of order. Data in the $q_{z}$ direction gives information about the film's critical angle (determined by the position of the Yoneda peak ${ }^{43}$ ) and out-of-plane geometry. For both 
cases, we used the 1-D paracrystalline domain model to approximate the interparticle correlation. This interparticle correlation model defines a long-range order that is gradually destroyed in a probabilistic manner. ${ }^{44}$ More information about the 1-D paracrystalline model and other models can be found elsewhere. ${ }^{45}$ 

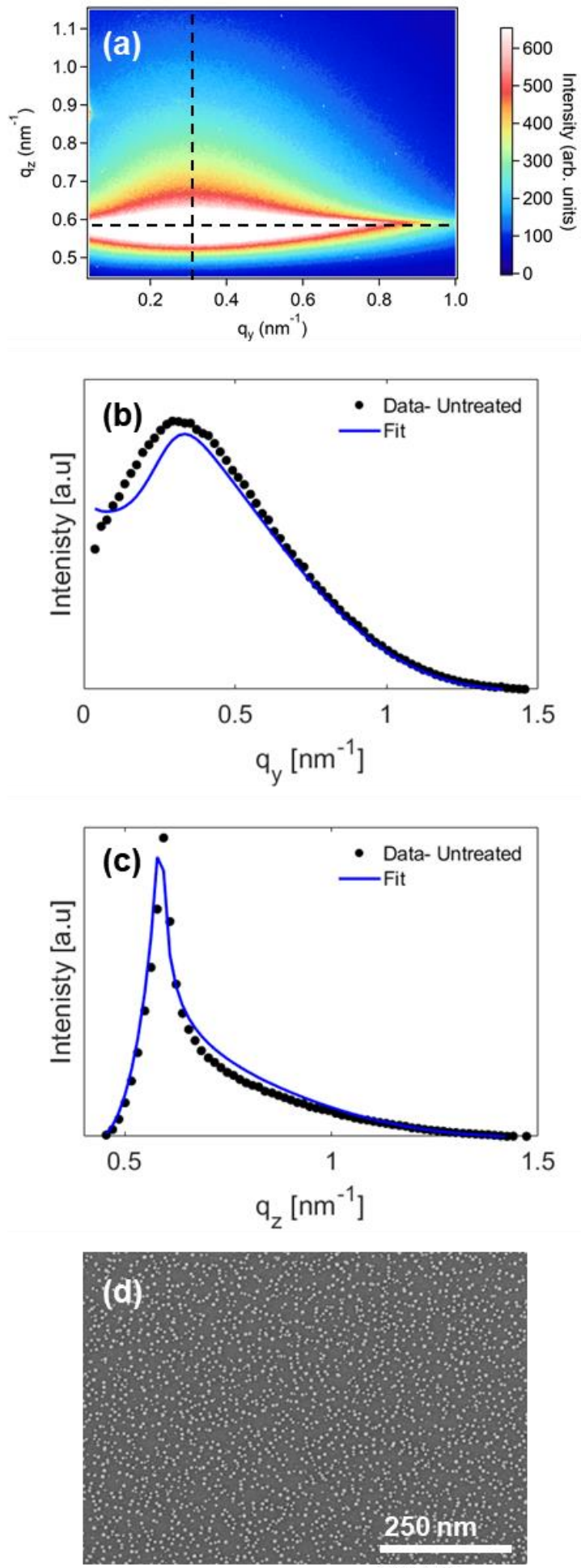
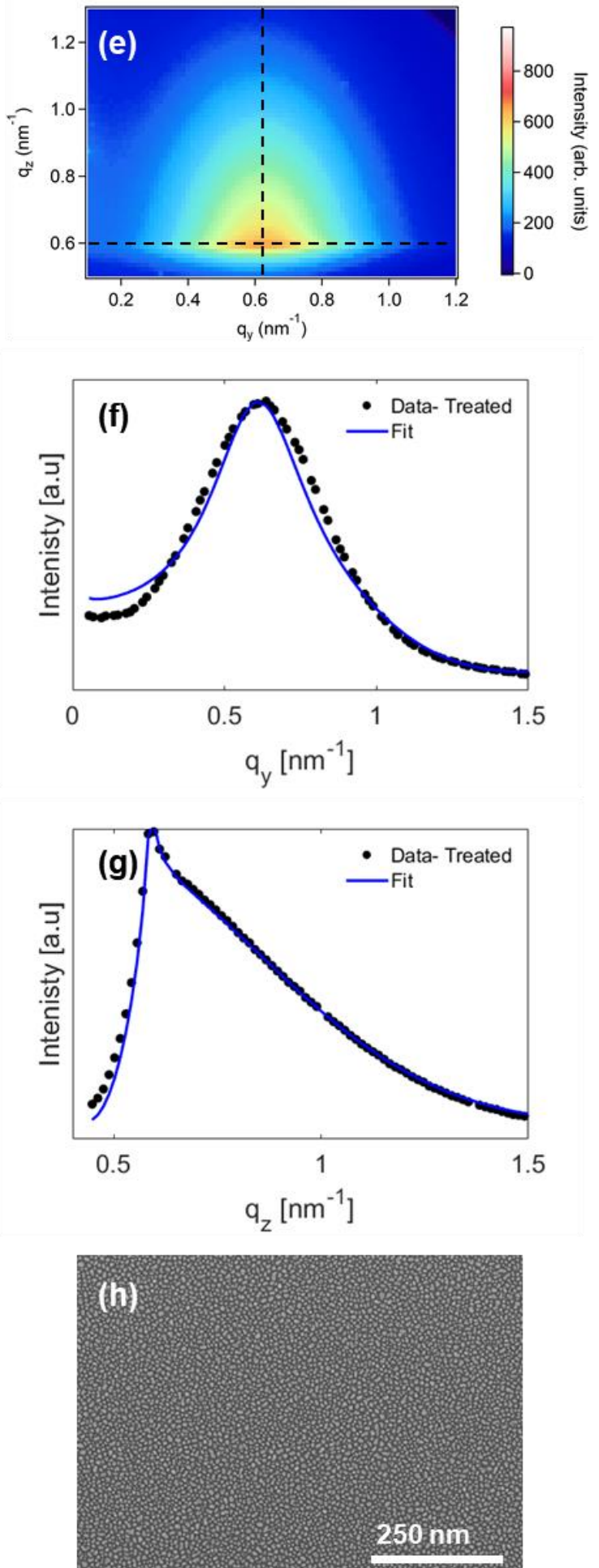

Figure 4. In the left column: for 40 cycles of Pt ALD on an untreated thermal $\mathrm{SiO}_{2}$ (a) GISAXS pattern (b) $\mathrm{q}_{y}$ line-cut and fit $\left(\alpha_{\mathrm{c}}=0.13^{\circ}\right)(\mathrm{c}) \mathrm{q}_{\mathrm{z}}$ line-cut and fit $\left(2 \theta_{\mathrm{f}}=0.3^{\circ}\right)(\mathrm{d}) \mathrm{SEM}$ image. In the right column: for 30 cycles of Pt ALD on a thermal SiO 2 treated with 1 pulse of $\mathrm{AlMe}_{2} \mathrm{Cl}(\mathrm{e})$ GISAXS pattern (f) $q_{\mathrm{y}}$ line-cut and fit $\left(\alpha_{\mathrm{c}}=0.17^{\circ}\right)(\mathrm{g}) \mathrm{q}_{\mathrm{z}}$ line-cut and fit $\left(2 \theta_{\mathrm{f}}=0.6^{\circ}\right) \quad(\mathrm{h})$ SEM image. 
Table 2. GISAXS best-fit parameters and SEM analysis results after 40 (untreated) and 30 (treated) Pt ALD cycles.

\begin{tabular}{c|c|c}
\hline Fit Parameter & Untreated & AlMe $2 \mathrm{Cl}$ Treated \\
\hline Particle Shape & Full Sphere & Truncated Sphere \\
$<d>[\mathrm{nm}]$ & 5.8 & 5.7 \\
$\frac{h}{<d>}$ & 1 & 0.8 \\
$D[\mathrm{~nm}]$ & 11.1 & 8.4 \\
$\frac{\sigma_{D}}{D}$ & 0.72 & 0.37 \\
Apparent Coverage (SEM) & $8.5 \%$ & $38.5 \%$ \\
Average Diameter [nm] (SEM) & 5.9 & 7.1 \\
Pt Loading Density $\left[\frac{\mathrm{nm}^{3}}{\text { Unit Area }}\right]$ & 525 & 1500 \\
\hline
\end{tabular}

a GISAXS fitting parameters: mean particle diameter $<\mathrm{d}>$, particle height $\mathrm{h}$, interparticle distance $\mathrm{D}$ and its standard deviation $\sigma_{D}$. Pt loading density is calculated in units of volume of Pt per unit area of the substrate, where the substrate unit area is $1000 \mathrm{~nm}^{2}$.

The GISAXS fit parameters and their comparison with the SEM analysis summarized in Table 2 provide interesting observations. The detailed SEM and GISAXS analyses show that the Pt NPs possess a different shape between the untreated and $\mathrm{AlMe}_{2} \mathrm{Cl}$-treated samples. The untreated NPs adopt a fully spherical shape, whereas the Pt NPs on the surface pre-treated with $\mathrm{AlMe}_{2} \mathrm{Cl}$ have the shape of a truncated sphere, with $\frac{h}{<d>}$ of 0.8 . In addition, SEM analysis shows that the coverage is much higher for the $\mathrm{AlMe}_{2} \mathrm{Cl}$-treated sample. Interestingly, the fitted diameter parameter of the treated substrate does not match between the SEM and GISAXS analysis. The average particle diameter of the treated sample is $20 \%$ larger than that of the untreated sample, as measured by SEM analysis, but by GISAXS analysis of $<d>$ it is $2 \%$ smaller. This discrepancy in diameter is too large to be attributed to small errors in GISAXS fitting or 
particle size measurement from the SEM image. Rather, we attribute this difference to the fact that particle size determination from GISAXS is more sensitive to the coherent scattering within one NP, whereas SEM cannot generally resolve a NP that may consist of several smaller, coalesced NPs. For further insight, we looked at the number of NPs per unit area by SEM, and at the critical angle $\left(\alpha_{c}\right)$ values of the film as determined by the GISAXS Yoneda peak (Figure 5).
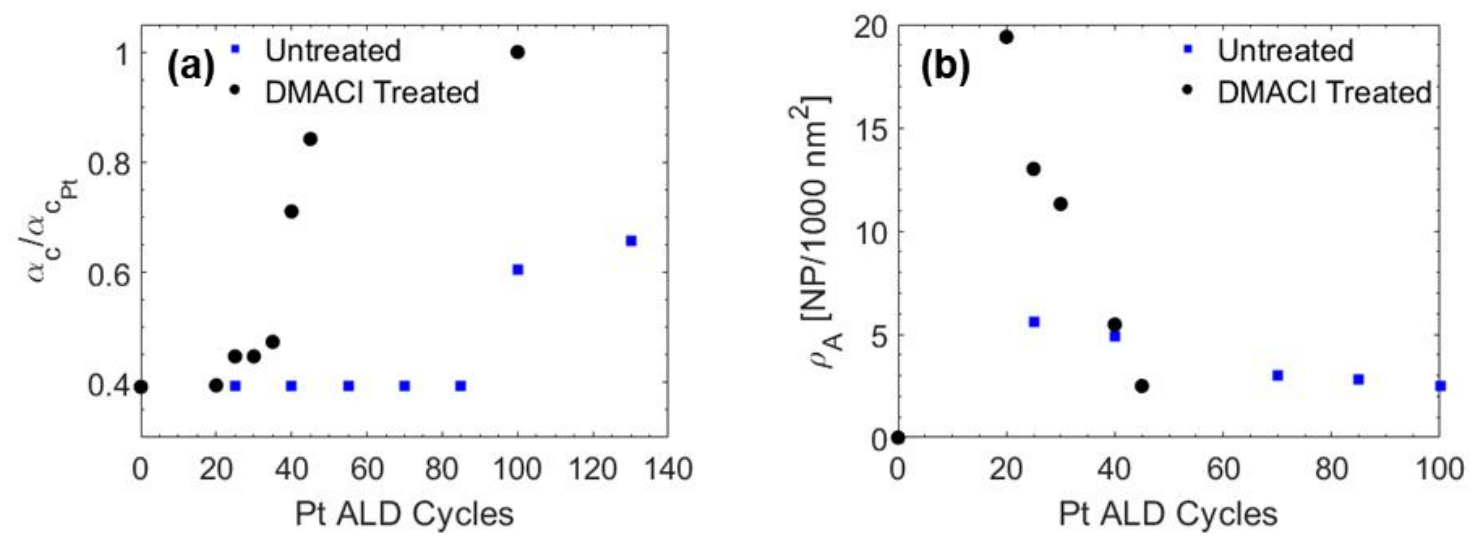

Figure 5. (a) Critical angle extracted from GISAXS data of ALD-grown Pt on thermal $\mathrm{SiO}_{2}$ as a function of cycle number, normalized to the bulk Pt critical angle at X-ray energy of $12 \mathrm{keV}$. (b) NP areal density ( $\rho A$ ) as a function of number of Pt ALD cycles, as measured by SEM. Data for both untreated and $\mathrm{AIMe}_{2} \mathrm{Cl}$-treated $\mathrm{SiO}_{2}$ samples are shown.

The measured $\alpha_{c}$ is a weighted average of the $\mathrm{Pt}$ and $\mathrm{SiO}_{2}$ substrate critical angles. Therefore, the increase of $\alpha_{c}$ as a function of cycle number directly reflects the ALD Pt domain growth and coalescence processes. According to the data in Figure $5 \mathrm{a}$, large $\mathrm{Pt}$ domains form on the treated surface after 40 cycles, compared to 100 cycles for the untreated sample. The areal density extracted from SEM in Figure $5 b$ shows a sharp drop as a function of cycle number on the treated substrates, compared to a slow decrease for the untreated substrates. The rapid rate of areal density decrease in the treated sample is indicative of rapid and significant NP coalescence in those deposits. This process of 
NP coalescence evident in Figure $5 b$ leads to the formation of the large Pt domains at low cycle numbers observed on the treated substrates as detected from the data in Figure 5a.

We therefore postulate that the difference in average particle size extracted from SEM versus GISAXS is a result of NP coalescence. Coalescence will lead to fewer discrete NPs as measured by SEM. However, grain boundary formation between these coalesced NPs would lead to incoherent X-ray scattering, resulting in their detection as separate NPs by GISAXS. ${ }^{46}$ Consequently, the particle size extracted from GISAXS of the treated sample is significantly smaller than that extracted by SEM. Since grain boundaries primarily affect the coherent scattering in the in-plane direction, we can use the coherent scattering in the out-of-plane direction as an estimation of the average NP height. Subsequently, by calculating the volume of the NPs as spheres in the case of the untreated substrates, and as truncated spheres in the case of the treated substrates, we can estimate the Pt loading density (in units of total Pt volume in $\mathrm{nm}^{3}$ per substrate unit area of $1000 \mathrm{~nm}^{2}$ ) by the following equations:

$$
\begin{gathered}
\text { Loading }_{\text {untreated }}\left(\frac{n m^{3}}{1000 n m^{2}}\right)=\frac{4}{3} \pi\left(\frac{<d>}{2}\right)^{3} *\left(\text { NPs per unit area } a_{S E M}\right) \\
\text { Loading }_{\text {treated }}\left(\frac{n m^{3}}{1000 n m^{2}}\right)=\pi * h_{\text {GISAXS }}^{2} * \frac{\frac{3}{2}<d>_{S E M}-h_{\text {GISAXS }}}{3} *\left(N P \text { s per unit area } a_{S E M}\right)
\end{gathered}
$$

where the subscripts indicate the method used to extract these parameters. According to this calculation, the total Pt loading density (presented in Table 2) on the untreated and treated substrates are approximately $525 \mathrm{~nm}^{3} /$ (unit area) and $1500 \mathrm{~nm}^{3} /$ (unit area) 
respectively. This loading corresponds to an average value of approximately $13 \mathrm{~nm}^{3} /$ (unit area) and $50 \mathrm{~nm}^{3} /$ (unit area) per cycle for the untreated and treated substrates, respectively. The data indicate an almost 4-fold increase in the average loading per cycle on the treated substrate. It is important to note that if out-of-plane grain boundaries do form on the treated substrates, the analysis presented above would result in an underestimation of the Pt loading density on the treated substrates. In this case, the difference in loading between the treated and untreated substrates would be even larger.

The shapes of the Pt NPs give further insight into the interaction between the Pt particles and the substrate. Recall that the shape of Pt NPs on the treated substrates was best modeled as a truncated sphere $\left(\frac{h}{\langle d\rangle}<1\right)$, whereas the NP shape on the untreated substrates was best modeled as a full sphere $\left(\frac{h}{\langle d\rangle}=1\right)$. This difference in shape indicates that the NPs have a higher degree of wetting on the treated surface. The higher degree of wetting could be a result of higher adhesion energy between the NPs and the functionalized surface. ${ }^{47}$ In principle, higher adhesion energies would result in lower atomic and NP diffusion, which could explain the higher NP densities and loadings observed..$^{48}$ Grillo et al.'s simulations showed that larger metal loadings could be achieved on surfaces where NP diffusion (but not adatom diffusion) is supressed. ${ }^{49}$ On the other hand, Dendooven et al. showed that $\mathrm{O}_{2}$-based diffusion-mediated and $\mathrm{N}_{2}$-plasma-based diffusion-suppressed Pt ALD both lead to similar loadings of $\mathrm{Pt}$ on $\mathrm{SiO}_{2 .}{ }^{50}$ This leads us to conclude that the nearly 4 -fold increase in average Pt loading per cycle resulting from the surface treatment can at most be only partially accounted for by lower NP diffusion alone. We therefore assert that the surface pre-treatment leads to enhanced chemisorption of the $\mathrm{MeCpPtMe}_{3}$ precursor on the functionalized surface. 
NP shape and size alone are not sufficient to understand the full picture of NP growth, since they lack information regarding the NP's surroundings. Modeling of the interparticle correlation as obtained from GISAXS measurements provides information about the degree of ordering of NPs on the surface as well as their average center-tocenter distance and its standard deviation. All GISAXS patterns were modeled using the 1-D paracrystal with LMA based on DWBA theory. The higher qy peak position in the horizontal line-cut of the treated sample (Figure 4f) compared to the untreated sample (Figure 4b) indicates a smaller center-to-center distance, D. The small center-to-center distance that is seen for the treated substrates (Table 2) agrees with the conclusion (based on the discrepancy in particle size modeled by GISAXS compared to the size measured by SEM) that Pt NPs on the treated substrate coalesce at a faster rate than the NPs on the untreated substrate. This coalescence leads to larger particles observed by SEM but which are comprised of a cluster of separate NPs at very close proximity (i.e. small center-to-center distance) giving rise to the incoherent X-ray scattering in GISAXS.

The GISAXS analysis also provides insight into the ordering of NPs on the surface. Within the 1D paracrystal model, the significantly smaller $\frac{\sigma_{D}}{D}$ of the interparticle correlation function on the treated substrates indicates a higher degree of NP ordering (i.e., a narrower distribution of the center-to-center distance between NPs) on that surface. ${ }^{51} \mathrm{We}$ interpret the $\frac{\sigma_{D}}{D}$ results from GISAXS in the following way. In $\mathrm{O}_{2}$-based Pt ALD, NP growth has been reported to be a NP diffusion-mediated process. ${ }^{50}$ This diffusion is a result of NP surface mobility, which generally decreases with increasing NP size and higher surface-adhesion energies. ${ }^{52}$ Hence, the sparsely packed, small NPs diffusing on the surface of the untreated substrate will diffuse more readily, which could result in a higher 
variance of center-to-center NP distance, In contrast, the densely packed, large NPs present on the treated substrate will undergo less diffusion. In support of this proposed explanation, Dendooven et al. reported larger uncertainties in GISAXS-fitted center-tocenter distances of $\mathrm{O}_{2}$-based diffusion-mediated Pt ALD compared to the $\mathrm{N}_{2}$ plasmabased Pt ALD, where diffusion was suppressed. The larger variance in center-to-center NP distances can result from a mixture of areas where the NPs are closely packed and areas where NPs are sparsely packed. Since Pt NPs are significantly more active towards precursor chemisorption than the $\mathrm{SiO}_{2}$ surface, the areas in which NPs are sparsely packed may not be fully filled, leading to films with pinoles.

Figure 6 illustrates this growth mechanism. First, the SEM data clearly show that the growth mechanism of Pt ALD on the both the treated and untreated surfaces is by island growth. The data, summarized in Table 2, further show that NPs on the treated surface form large and densely packed truncated spheres, compared to dispersed and smaller full spheres on the untreated surface. The larger NPs formed on the treated surfaces have less mobility, increasing the degree of order on the surface. This larger degree of ordering will result in better space filling during the earlier stages of film growth. Since the $\mathrm{SiO}_{2}$ surface is significantly more inert to Pt ALD compared to the alreadydeposited catalytic Pt film surface, Pt will preferentially deposit on the existing Pt film/NPs rather than on the substrate. Hence, poor space filling early on will eventually result in films with a higher density of pinholes even in mid-range thicknesses, as observed in the SEM images of the untreated and $\mathrm{AlMe}_{2} \mathrm{Cl}$ treated samples in the SI (Figure S5). 


\section{$\underline{\text { Untreated }}$}

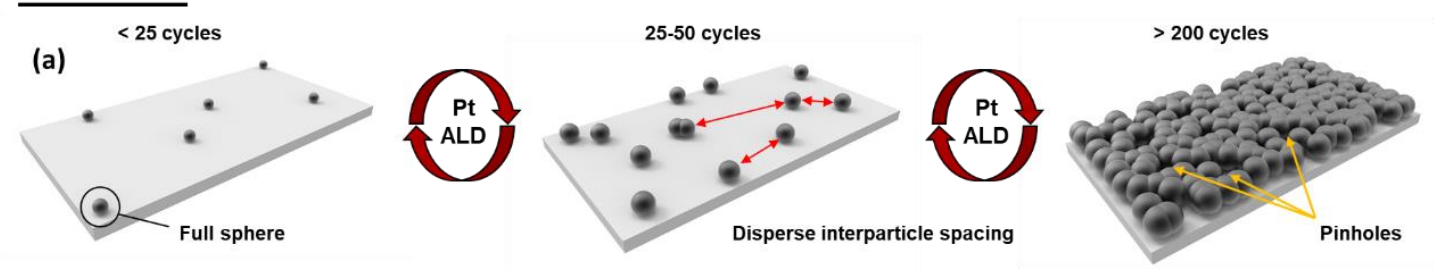

\section{$\underline{\text { Treated }}$}
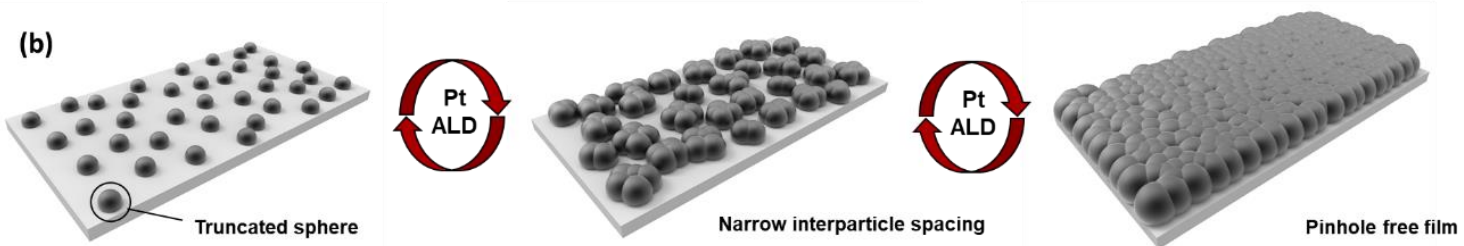

Figure 6. Illustration of the Pt ALD growth mechanism on a thermal $\mathrm{SiO}_{2}$ substrate that is a) untreated b) treated with a single pulse of an alkylated organometallic precursor $\left(\mathrm{ZnEt}_{2} / \mathrm{AlMe}_{3} / \mathrm{AlMe}{ }_{2} \mathrm{Cl}\right)$.

\section{Conclusions}

In this work, we demonstrate dramatically changed growth characteristics of $\mathrm{Pt}$ ALD performed on thermally grown $\mathrm{SiO}_{2}$ pre-treated with a single pulse of a metalorganic precursor. We show that continuous and pinhole free films can be deposited at lower cycle numbers on substrates that have been treated with a single pulse of various metalorganic precursors. Due to the self-limiting behavior of the pre-treatment metalorganic precursor chemisorption, this nucleation enhancement is achieved while incorporating less than a single monolayer of the pre-treatment molecule. The enhancement effect is significant in the case of the alkylated precursors, $\mathrm{ZnEt}_{2}, \mathrm{AlMe}_{3}$ and $\mathrm{AlMe}_{2} \mathrm{Cl}$, while minimal in the halogenated precursors, $\mathrm{AlCl}_{3}$ and $\mathrm{TiCl}_{4}$. Although more studies must be done to confirm the reaction mechanism, we hypothesize that the observed increase in chemisorption of $\mathrm{MeCpPtMe}_{3}$ on the treated substrate originates from a Brønsted acid-base reaction between the alkylated metalorganic precursor chemisorbed to the surface and gaseous $\mathrm{MeCpPtMe}$. 
SEM and GISAXS measurements are performed to study the growth mechanism of Pt ALD on treated and untreated substrates. Although the growth mechanism both with and without the pre-treatment is island growth, the alkylated metalorganic precursor pulse results in the growth of highly dense, ordered Pt nanoparticles at low cycle numbers. GISAXS Yoneda peak analysis of the critical angle of the film shows that the Pt film on the pre-treated substrate coalesces at earlier stages of ALD, resulting in large Pt domains. The large particle domains have a lower surface mobility, leading to continuous and pinhole free films, another benefit of the metalorganic pre-treatment methodology introduced here.

\section{Experimental Procedures}

Substrate Preparation and ALD Processes. A custom-made ALD reactor controlled by LabVIEW software was used for this study. A showerhead inlet and vacuum pumping lines were connected to the top and bottom of the reactor, respectively. The substrate was placed on a 4-in. diameter substrate heater that was maintained at $300{ }^{\circ} \mathrm{C}$ during all processes. $\mathrm{MeCpPtMe}_{3}$ (Strem Chemicals, Inc.) and $\mathrm{O}_{2}$ (99.99\% purity) were used as the Pt precursor and counter reactant, respectively. The Pt precursor was contained in a metal bubbler and its temperature was held at $55^{\circ} \mathrm{C}$ to obtain a proper vapor pressure during processing. The delivery line was heated to $15^{\circ} \mathrm{C}$ higher than that of the Pt bubbler to prevent precursor condensation. The precursor vapor was carried into the reaction chamber with $\mathrm{N}_{2}$ carrier gas controlled by mass flow controller at $30 \mathrm{sccm} . \mathrm{N}_{2}$ gas at the same flow rate was also used for purging excess gas molecules and byproducts between each precursor and counter reactant exposure step. The Pt ALD cycle consisted of a 2 second precursor pulse, a 30 second $\mathrm{N}_{2}$ purge, a 2 second co-reactant pulse, and an 
additional 30 second $\mathrm{N}_{2}$ purge. Bubblers containing diethylzinc (ZnEt2), trimethylaluminum $\left(\mathrm{AlMe}_{3}\right)$, dimethylaluminum chloride $\left(\mathrm{AlMe}_{2} \mathrm{Cl}\right)$, trichloro aluminum $\left(\mathrm{AlCl}_{3}\right)$ and titanium tetrachloride $\left(\mathrm{TiCl}_{4}\right)$ were maintained at room temperature. The prepulse of these coordination complexes consisted of a 1 second pulse followed by a 30 second $\mathrm{N}_{2}$ purge. Further information on the chamber configurations and Pt ALD process can be found elsewhere..$^{53}$

The $\mathrm{Si}(001)$ wafers were cleaned in a $2 \% \mathrm{HF}$ in water solution, then subjected to thermal oxidation in $\mathrm{O}_{2}$ at atmospheric pressure at $1050{ }^{\circ} \mathrm{C}$ for 2 hours, resulting in an oxide thickness of $0.13 \mu \mathrm{m}$. The oxidized samples were cut to into $1 \mathrm{~cm}^{2}$ pieces and cleaned by sequentially dipping in acetone, isopropanol and deionized $\mathrm{H}_{2} \mathrm{O}$, followed by a 5 minutes UV-ozone clean. The samples were then placed in the ALD chamber under nitrogen at $300{ }^{\circ} \mathrm{C}$ for 30 minutes prior to deposition.

Analytical Methods. Grazing incidence small angle scattering was carried out at the Stanford Synchrotron Radiation Lightsource (SSRL). The measurements where conducted at beam line 1-5 with $12 \mathrm{keV}$ X-rays and a Rayonix 165 2D CCD detector. The samples were positioned at a grazing angle of $0.4^{\circ}$ with respect to the $x$-ray beam and held at a distance of 2.8 meters away from the detector. The position was calibrated using a silver behenate reference sample. The direct beam and reflected beam were blocked with a tungsten rod. The $\mathrm{q}$ range obtained was $0.01-1.5 \mathrm{~nm}^{-1}$. The 2D image data was calibrated using the Nika software ${ }^{54}$ and was converted to individual slices in the qy and $q_{z}$ directions using the FitGISAXS software. ${ }^{55}$ The data was analyzed using the IsGISAXS software package. ${ }^{44}$ All fit calculations were done under the distorted wave-born approximation (DWBA) for grazing incidence geometry. ${ }^{56,57}$ The structure factor used for 
all calculations is the 1-D paracrystal model (using gaussian statistics) with the local monodisperse approximation (LMA). ${ }^{58}$ All simulations were done with a lognormal NP size distribution. ${ }^{50}$

FEI Magellan 400 XHR Scanning Electron Microscope with FEG source was used to image surface morphology. ${ }^{59}$ All SEM images were recorded using an accelerating voltage of $10 \mathrm{kV}$ and an in-lens secondary electron imaging mode. NP size and coverage were determined using ImageJ software. The planar SEM images were converted into threshold images to define the NPs, and the resulting NP diameter, total area, and number of NPs were extracted. In some cases, coverages determined from SEM images were given as a range rather than a single value if a low image contrast contributed uncertainty to the value. The calculation of the total area of Pt NPs as a function of number of ALD cycles from the nucleation model was performed using MATLAB 2016b. The calculated results were fitted to experimental results using the same software. ${ }^{60}$

\section{Supplemental Information}

Supplemental Information can be found online at

\section{Acknowledgments}

This work was supported by the U.S. Department of Energy under Award Number DESC0004782. We thank professor Bruce M. Clemens for fruitful discussions on nanoparticle growth mechanisms. Use of Stanford Synchrotron Radiation Lightsource, SLAC National Accelerator Laboratory, was supported by the U.S. Department of Energy, Office of Science, Office of Basic Energy Sciences under Contract No. DE-AC0276SF00515. Part of this work was performed at the Stanford Nano Shared Facilities (SNSF), supported by the National Science Foundation under award ECCS-1542152. 


\section{Author Contributions}

Conceptualization, C.dP. and S.F.B.; Methodology, C.dP.; Formal Analysis, C.dP. and L.Z.; Investigation Cd.P. and L.Z.; Writing - Original Draft, C.dP.; Writing - Review \& Editing, C.dP., L.Z., N.E.R., and S.F.B.; Funding Acquisition, S.F.B.; Supervision, N.E.R., and S.F.B.

\section{Declaration of Interests}

The authors declare no competing interests.

\section{References}

(1) Kim, H.; Lee, H. B. R.; Maeng, W. J. Applications of Atomic Layer Deposition to Nanofabrication and Emerging Nanodevices. Thin Solid Films. 2009, 517 (8), 2563-2580.

(2) O’Neill, B. J.; Jackson, D. H. K.; Lee, J.; Canlas, C.; Stair, P. C.; Marshall, C. L.; Elam, J. W.; Kuech, T. F.; Dumesic, J. A.; Huber, G. W. Catalyst Design with Atomic Layer Deposition. ACS Catal. 2015, 5 (3), 1804-1825.

(3) Marichy, C.; Bechelany, M.; Pinna, N. Atomic Layer Deposition of Nanostructured Materials for Energy and Environmental Applications. Adv. Mater. 2012, 24 (8), 1017-1032.

(4) Shi, J.; Li, Z.; Kvit, A.; Krylyuk, S.; Davydov, A. V.; Wang, X. Electron Microscopy Observation of $\mathrm{TiO}_{2}$ Nanocrystal Evolution in High-Temperature Atomic Layer Deposition. Nano Lett. 2013, 13 (11), 5727-5734.

(5) Zhang, Z.; Lagally, M. G. Atomistic Processes in the Early Stages of Thin-Film Growth. Science (80-. ). 1997, 276 (5311), 377-383.

(6) Clancey, J. W.; Cavanagh, A. S.; Kukreja, R. S.; Kongkanand, A.; George, S. M. Atomic Layer Deposition of Ultrathin Platinum Films on Tungsten Atomic Layer Deposition Adhesion Layers: Application to High Surface Area Substrates. Cit. J. Vac. Sci. Technol. A 2015, 33, 1-130.

(7) Yamamichi, S.; Lesaicherre, P. Y.; Yamaguchi, H.; Takemura, K.; Sone, S.; Yabuta, H.; Sato, K.; Tamura, T.; Nakajima, K.; Ohnishi, S.; et al. A Stacked Capacitor Technology with ECR Plasma MOCVD (Ba,Sr)TiO 3 and $\mathrm{RuO}_{2} / \mathrm{Ru} / \mathrm{TiN} / \mathrm{TiSia}$; Storage Nodes for Gb-Scale DRAM's. IEEE Trans. Electron Devices 1997, 44 (7), 1076-1083.

(8) Borup, R.; Meyers, J.; Pivovar, B.; Kim, Y. S.; Mukundan, R.; Garland, N.; Myers, D.; Wilson, M.; Garzon, F.; Wood, D.; et al. Scientific Aspects of Polymer Electrolyte Fuel Cell Durability and Degradation. Chem. Rev. 2007, 107 (10), 3904-3951. 
(9) George, S. M. Atomic Layer Deposition: An Overview. Chem. Rev. 2010, 110 (1), 111-131.

(10) Goldstein, D. N.; George, S. M. Enhancing the Nucleation of Palladium Atomic Layer Deposition on $\mathrm{Al}_{2} \mathrm{O}_{3}$ Using Trimethylaluminum to Prevent Surface Poisoning by Reaction Products. Appl. Phys. Lett. 2009, 95 (14), 143106.

(11) Minjauw, M. M.; Rijckaert, H.; Driessche, I. Van; Detavernier, C.; Dendooven, J. Nucleation Enhancement and Area-Selective Atomic Layer Deposition of Ruthenium Using $\mathrm{RuO}_{4}$ and $\mathrm{H}_{2}$ Gas. Chem. Mater. 2019, 31 (5), 1491-1499.

(12) Hwang, Y.; Nguyen, B.-M.; Dayeh, S. A. Atomic Layer Deposition of Platinum with Enhanced Nucleation and Coalescence by Trimethylaluminum Pre-Pulsing. Appl. Phys. Lett. 2013, 103 (26), 263115.

(13) Rai, V. R.; Vandalon, V.; Agarwal, S. Surface Reaction Mechanisms during Ozone and Oxygen Plasma Assisted Atomic Layer Deposition of Aluminum Oxide. Langmuir 2010, 26 (17), 13732-13735.

(14) Setthapun, W.; Williams, W. D.; Kim, S. M.; Feng, H.; Elam, J. W.; Rabuffetti, F. A.; Poeppelmeier, K. R.; Stair, P. C.; Stach, E. A.; Ribeiro, F. H.; et al. Genesis and Evolution of Surface Species during Pt Atomic Layer Deposition on Oxide Supports Characterized by in Situ XAFS Analysis and Water - Gas Shift Reaction. 2010, No. Cvd, 9758-9771.

(15) Lee, H. B. R.; Bent, S. F. Microstructure-Dependent Nucleation in Atomic Layer Deposition of Pt on $\mathrm{TiO}_{2}$. Chem. Mater. 2012, 24 (2), 279-286.

(16) Lee, H. B. R.; Pickrahn, K. L.; Bent, S. F. Effect of $\mathrm{O}_{3}$ on Growth of Pt by Atomic Layer Deposition. J. Phys. Chem. C 2014, 118 (23), 12325-12332.

(17) Hadjiivanov, K. Identification and Characterization of Surface Hydroxyl Groups by Infrared Spectroscopy. Adv. Catal. 2014, 57, 99-318.

(18) Sandupatla, A. S.; Alexopoulos, K.; Reyniers, M. F.; Marin, G. B. Ab Initio Investigation of Surface Chemistry of Alumina ALD on Hydroxylated $\gamma$-Alumina Surface. J. Phys. Chem. C 2015, 119 (23), 13050-13061.

(19) Kim, S.; Lee, S.; Ham, S. Y.; Ko, D. H.; Shin, S.; Jin, Z.; Min, Y. S. A Kinetic Study of ZnO Atomic Layer Deposition: Effects of Surface Hydroxyl Concentration and Steric Hindrance. Appl. Surf. Sci. 2019, 469, 804-810.

(20) Weckman, T.; Laasonen, K. First Principles Study of the Atomic Layer Deposition of Alumina by TMA-H ${ }_{2} \mathrm{O}-$ Process. Phys. Chem. Chem. Phys. 2015, 17 (26), 17322-17334.

(21) Mackus, A. J. M.; Garcia-Alonso, D.; Knoops, H. C. M.; Bol, A. A.; Kessels, W. M. M. Room-Temperature Atomic Layer Deposition of Platinum. Chem. Mater. 2013, $25(9), 1769-1774$.

(22) Brozena, A. H.; Oldham, C. J.; Parsons, G. N. Atomic Layer Deposition on Polymer Fibers and Fabrics for Multifunctional and Electronic Textiles. J. Vac. Sci. 
Technol. A Vacuum, Surfaces, Film. 2016, 34 (1), 010801.

(23) Aligned Carbon Nanotube Array Functionalization for Enhanced Atomic Layer Deposition of Platinum Electrocatalysts. Appl. Surf. Sci. 2012, 258 (13), 52125221.

(24) Lee, H. B. R.; Bent, S. F. Formation of Continuous Pt Films on the Graphite Surface by Atomic Layer Deposition with Reactive O3. Chem. Mater. 2015, 27 (19), 6802-6809.

(25) Dillon, A. C.; Ott, A. W.; Way, J. D.; George, S. M. Surface Chemistry of $\mathrm{Al}_{2} \mathrm{O}_{3}$ Deposition Using $\mathrm{Al}\left(\mathrm{CH}_{3}\right)_{3}$ and $\mathrm{H}_{2} \mathrm{O}$ in a Binary Reaction Sequence. Surf. Sci. 1995, 322 (1-3), 230-242.

(26) Goldstein, D. N.; McCormick, J. A.; George, S. M. $\mathrm{Al}_{2} \mathrm{O}_{3}$ Atomic Layer Deposition with Trimethylaluminum and Ozone Studied by in Situ Transmission FTIR Spectroscopy and Quadrupole Mass Spectrometry. J. Phys. Chem. C 2008, 112 (49), 19530-19539.

(27) Morrow, B. A.; A.J., M. Chemical Reactions at Silica Surfaces. J. Non-Crystalline Solid 1990, 120, 61-71.

(28) Kobayashi, S.; Busujima, T.; Nagayama, S. A Novel Classification of Lewis Acids on the Basis of Activity and Selectivity. Chem. - A Eur. J. 2000, 6 (19), 34913494.

(29) House, H. O. Modern Synthetic Reactions. Calif., W. A. Benjamin 1972.

(30) Bartram, M. E.; Michalske, T. A.; Rogers, J. W. A Reexamination of the Chemisorption of Trimethylaluminum on Silica. J. Phys. Chem. 1991, 95 (11), 4453-4463.

(31) Gerber, L. C. H.; Le Roux, E.; Törnroos, K. W.; Anwander, R. Elusive Trimethyllanthanum: Snapshots of Extensive Methyl Group Degradation in La-Al Heterobimetallic Complexes. Chem. - A Eur. J. 2008, 14 (31), 9555-9564.

(32) Dietrich, H. M.; Grove, H.; Törnroos, K. W.; Anwander, R. Multiple C-H Bond Activation in Group 3 Chemistry: Synthesis and Structural Characterization of an Yttrium Aluminum-Methine Cluster. J. Am. Chem. Soc. 2006, 128 (5), 1458-1459.

(33) Tebbe, F. N.; Parshall, G. W.; Reddy, G. S. Olefin Homologation with Titanium Methylene Compounds. J. Am. Chem. Soc. 1978, 100 (11), 3611-3613.

(34) Choi, D.; Yoo, M.; Lee, H. M.; Park, J.; Kim, H. Y.; Park, J.-S. A Study on the Growth Behavior and Stability of Molecular Layer Deposited Alucone Films Using Diethylene Glycol and Trimethyl Aluminum Precursors, and the Enhancement of Diffusion Barrier Properties by Atomic Layer Deposited $\mathrm{Al}_{2} \mathrm{O}_{3}$ Capping. ACS Appl. Mater. Interfaces 2016, 8 (19), 12263-12271.

(35) Schweitzer, N. M.; Hu, B.; Das, U.; Kim, H.; Greeley, J.; Curtiss, L. A.; Stair, P. C.; Miller, J. T.; Hock, A. S. Propylene Hydrogenation and Propane Dehydrogenation by a Single-Site $\mathrm{Zn}^{2+}$ on Silica Catalyst. ACS Catal. 2014, 4 (4), 1091-1098. 
(36) Camacho-Bunquin, J.; Aich, P.; Ferrandon, M.; Getsoian, A.; Das, U.; Dogan, F.; Curtiss, L. A.; Miller, J. T.; Marshall, C. L.; Hock, A. S.; et al. Single-Site Zinc on Silica Catalysts for Propylene Hydrogenation and Propane Dehydrogenation: Synthesis and Reactivity Evaluation Using an Integrated Atomic Layer DepositionCatalysis Instrument. J. Catal. 2017, 345, 170-182.

(37) Camacho-Bunquin, J.; Ferrandon, M.; Das, U.; Dogan, F.; Liu, C.; Larsen, C.; Platero-Prats, A. E.; Curtiss, L. A.; Hock, A. S.; Miller, J. T.; et al. Supported Aluminum Catalysts for Olefin Hydrogenation. ACS Catal. 2017, 7 (1), 689-694.

(38) McGrady, G. S.; Turner, J. F. C.; Ibberson, R. M.; Prager, M. Structure of the Trimethylaluminum Dimer As Determined by Powder Neutron Diffraction at Low Temperature. Organometallics 2000, 19 (21), 4398-4401.

(39) Beckmann, K. H.; Harrick, N. J. Hydrides and Hydroxyls in Thin Silicon Dioxide Films. J. Electrochem. Soc. 1971, 118 (4), 614.

(40) Geyer, S. M.; Methaapanon, R.; Johnson, R.; Brennan, S.; Toney, M. F.; Clemens, B.; Bent, S. Structural Evolution of Platinum Thin Films Grown by Atomic Layer Deposition. J. Appl. Phys. 2014, 116 (6), 064905.

(41) Naudon, A.; Thiaudiere, D. Grazing-Incidence Small-Angle Scattering. Morphology of Deposited Clusters and Nanostructure of Thin Films. J. Appl. Crystallogr. 1997, 30 (5), 822-827.

(42) Kaune, G.; Ruderer, M. A.; Metwalli, E.; Wang, W.; Couet, S.; Schlage, K.; Röhlsberger, R.; Roth, S. V.; Müller-Buschbaum, P. In Situ GISAXS Study of Gold Film Growth on Conducting Polymer Films. ACS Appl. Mater. Interfaces 2009, 1 (2), 353-360.

(43) Yoneda, Y. Anomalous Surface Reflection of X Rays. Phys. Rev. 1963, 131 (5), 2010-2013.

(44) Lazzari, R. IsGISAXS : A Program for Grazing-Incidence Small-Angle X-Ray Scattering Analysis of Supported Islands. J. Appl. Crystallogr. 2002, 35 (4), 406421.

(45) Leroy, F.; Lazzari, R.; Renaud, G. Effects of Near-Neighbor Correlations on the Diffuse Scattering from a One-Dimensional Paracrystal. Acta Crystallogr. Sect. A Found. Crystallogr. 2004, 60 (6), 565-581.

(46) Nix, W. D.; Clemens, B. M. Crystallite Coalescence: A Mechanism for Intrinsic Tensile Stresses in Thin Films. J. Mater. Res. 1999, 14 (08), 3467-3473.

(47) Campbell, C. T.; Sellers, J. R. V. Anchored Metal Nanoparticles: Effects of Support and Size on Their Energy, Sintering Resistance and Reactivity. Faraday Discussions., 2013, 9-30.

(48) Soethoudt, J.; Grillo, F.; Marques, E. A.; van Ommen, J. R.; Tomczak, Y.; Nyns, L.; Van Elshocht, S.; Delabie, A. Diffusion-Mediated Growth and Size-Dependent Nanoparticle Reactivity during Ruthenium Atomic Layer Deposition on Dielectric Substrates. Adv. Mater. Interfaces 2018, 5 (24), 1800870. 
(49) Grillo, F.; Moulijn, J. A.; Kreutzer, M. T.; van Ommen, J. R. Nanoparticle Sintering in Atomic Layer Deposition of Supported Catalysts: Kinetic Modeling of the Size Distribution. Catal. Today 2018, 316, 51-61.

(50) Dendooven, J.; Ramachandran, R. K.; Solano, E.; Kurttepeli, M.; Geerts, L.; Heremans, G.; Rongé, J.; Minjauw, M. M.; Dobbelaere, T.; Devloo-Casier, K.; et al. Independent Tuning of Size and Coverage of Supported Pt Nanoparticles Using Atomic Layer Deposition. Nat. Commun. 2017, 8 (1), 1074.

(51) Rebollar, E.; Vázquez de Aldana, J. R.; Martín-Fabiani, I.; Hernández, M.; Rueda, D. R.; Ezquerra, T. A.; Domingo, C.; Moreno, P.; Castillejo, M. Assessment of Femtosecond Laser Induced Periodic Surface Structures on Polymer Films. Phys. Chem. Chem. Phys. 2013, 15 (27), 11287.

(52) Grillo, F.; Van Bui, H.; Moulijn, J. A.; Kreutzer, M. T.; Van Ommen, J. R. Understanding and Controlling the Aggregative Growth of Platinum Nanoparticles in Atomic Layer Deposition: An Avenue to Size Selection. J. Phys. Chem. Lett. 2017, 8 (5), 975-983.

(53) Jiang, X.; Bent, S. F. Area-Selective ALD with Soft Lithographic Methods: Using Self-Assembled Monolayers to Direct Film Deposition. J. Phys. Chem. C 2009, 113 (41), 17613-17625.

(54) Ilavsky, J. Nika: Software for Two-Dimensional Data Reduction. J. Appl. Crystallogr. 2012, 45 (2), 324-328.

(55) Babonneau, D. FitGISAXS : Software Package for Modelling and Analysis of GISAXS Data Using IGOR Pro. J. Appl. Crystallogr. 2010, 43 (4), 929-936.

(56) Busch, P.; Rauscher, M.; Smilgies, D. M.; Posselt, D.; Papadakis, C. M. GrazingIncidence Small-Angle X-Ray Scattering from Thin Polymer Films with Lamellar Structures - the Scattering Cross Section in the Distorted-Wave Born Approximation. J. Appl. Crystallogr. 2006, 39 (3), 433-442.

(57) Rauscher, M.; Salditt, T.; Spohn, H. Small-Angle x-Ray Scattering under Grazing Incidence: The Cross Section in the Distorted-Wave Born Approximation. Phys. Rev. B 1995, 52 (23), 16855-16863.

(58) Revenant, C.; Leroy, F.; Lazzari, R.; Renaud, G.; Henry, C. R. Quantitative Analysis of Grazing Incidence Small-Angle x-Ray Scattering: $\mathrm{Pd} / \mathrm{MgO}(001)$ Growth. Phys. Rev. B - Condens. Matter Mater. Phys. 2004, 69 (3), 1-17.

(59) Schneider, C. A.; Rasband, W. S.; Eliceiri, K. W. NIH Image to Image J: 25 Years of Image Analysis. Nat. Methods 2012, 9 (7), 671-675.

(60) Lee, H. B. R.; Mullings, M. N.; Jiang, X.; Clemens, B. M.; Bent, S. F. NucleationControlled Growth of Nanoparticles by Atomic Layer Deposition. Chem. Mater. 2012, 24 (21), 4051-4059. 